\title{
How do audiologists respond to emotional and psychological concerns raised in the
} audiology setting? Three case vignettes

Authors: Rebecca J Bennett*, ${ }^{\dagger}$, Carly J Meyer ${ }^{\circ}$, Brooke Ryan ${ }^{\circ}$, Robert H Eikelboom*,+,‡

* Ear Science Institute Australia, Subiaco, Australia, ${ }^{\dagger}$ Ear Sciences Centre, The University of Western Australia, Nedlands, Australia, ${ }^{\circ}$ School of Health and Rehabilitation Sciences, University of Queensland, Brisbane, Australia, ${ }^{\ddagger}$ Department of Speech Language Pathology and Audiology, University of Pretoria, Pretoria, South Africa.

Address correspondence to Rebecca Bennett, Ear Science Institute Australia, Suite 1, Level 2, 1 Salvado Road, Subiaco, WA 6008, Australia. Tel: +61 863804900 . Fax: +61 863804901. Email: bec.bennett@earscience.org.au

\section{Conflicts of Interest and Sources of Funding} The authors report no conflicts of interest. This study was funded by the Ear Science Institute Australia.

$\mathrm{RB}$ and $\mathrm{CM}$ were major contributors to the project conceptualisation and design. $\mathrm{RB}$ managed the project, including participant recruitment and data collection. RB and CM managed data analysis. RB was a major contributor in writing the manuscript. All authors discussed the results and implications and commented on the manuscript at all stages. 
ABSTRACT

Objectives: Emotional and psychological well-being are essential to overall health but there

is little research showing how to approach emotional and psychological concerns in the audiological setting. This study investigated audiologists' self-reported clinical behaviours in response to emotional and psychological concerns and/or symptoms raised by audiology clients.

Design: A sample of 83 Australia-based audiologists completed a survey including vignettes presenting older adults with hearing loss and experiencing symptoms consistent with either depression or grief. Content analysis was used to explore: (i) audiologists' self-reported usual response when clients present with emotional and psychological concerns and/or symptoms in the audiological setting; (ii) audiologists' ability to identify and describe psychological symptoms; and (iii) audiologists' self-reported clinical behaviours relating to client referral for psychological support.

Results: When asked to describe their usual clinical course of action in response to the vignettes, over half of the audiologists described actions that address the clients concerns related to psychological well-being. Where audiologists described how they would provide psychological support, they described modifications to the audiological rehabilitation program including involving significant others in the rehabilitation process, recommending additional support outside of the audiology setting (such as General Practitioner or psychologists), and providing emotional support and counselling. When prompted, the majority of participants recognised the two cases with depression as having a mental health condition; however $48 \%$ of participants indicated the control case as also having a mental

60 health condition. When asked directly, the majority of audiologists indicated that they 61 would refer the three vignettes for specialist support; however, less than one third 
62 described referral to a GP and less than 5\% described referral to a mental health

63 professional as their normal course of action in the open response item. Twenty five

64 different professions/people were reported as potential sources for referral.

65 Conclusion: These findings support the need for further training and/or resources for

66 audiologists to enable them to appropriately detect, describe and refer for emotional and

67 psychological concerns and/or symptoms raised by clients' in the audiology setting.

68 


\section{INTRODUCTION}

Untreated psychological disorders incur major economic costs and personal suffering (Hilton et al. 2010; Laplagne et al. 2007). Without an intervention, the World Health Organization estimates that depression will be the number one health concern in both the developed and developing nations by 2030 (World Health Organization, 2008). Psychological disorders and hearing loss are common, costly and debilitating health problems among the increasing population of older adults (Barker et al. 2017; Lawrence et al. 2019; Mokdad et al. 2018). The number of older adults (over 55 years of age) experiencing psychiatric disorders is increasing; in the USA $11.4 \%$ have an anxiety disorder, $6.8 \%$ a mood disorder, $5.6 \%$ major depression, and $14.3 \%$ have one or more personality disorders (Reynolds et al. 2015). In Australia, approximately $45 \%$ of adults experience mental health concerns during their life, with late-life depression (the onset of depression in the later years of life) affecting between 10 to $15 \%$ of Australians over the age of 65 years (Australian Bureau of Statistics, 2008). Depression in older adults is associated with poor physical health (Penninx et al. 2000), increased use of medical services (Pearson et al. 1999), and is one of the major causes of suicide in this age group (Australian Bureau of Statistics, 2008; Lebowitz et al. 1997). Evidence suggests that depression in older adults does not frequently result from a single event in isolation, but rather from a combination of vulnerabilities between biological changes associated with ageing (e.g., cardiovascular disease, neurodegeneration) and increased frequency of stressful life events (e.g., death of family/friends) that are less commonly experienced during earlier years of life (Fiske et al. 2009).

Hearing loss has recently been described as a chronic stressor in individuals' lives, contributing to the development of depression (West, 2017). The independent relationship between hearing loss and depression has been documented in clinical and population 
studies (Han et al. 2018; Huang et al. 2010; Jayakody et al. 2018; Simning et al. 2018), with hearing loss increasing the risk of depression by $47 \%$ in older adults (Lawrence et al. 2018). However, the mechanism(s) potentially contributing to this association are currently not well understood. It is hypothesized that the hearing difficulties associated with hearing loss cause people to withdraw leading to increased feelings of loneliness and social isolation, which may contribute to development of depressive symptoms (Pronk et al. 2014; West, 2017). Evidence also suggests that the economic burden imposed on individuals by the presence of a hearing loss may affect psychological well-being (Hogan et al. 2009). The comorbidity of hearing loss and depression is of particular concern, as they are reported to be the two leading causes of years of life with disability among adults in high-income countries (Li et al. 2014; World Health Organization, 2017).

Within the current General Practitioner (GP) led model of care less than a half of people with depression receive treatment (Parslow et al. 2011), and formal diagnosis and treatment often only occurs late in the illness, after many years of suffering (Wilkinson and Izmeth 2012). Delay among those who eventually seek treatment ranges from six to eight years for mood disorders and nine to 23 years for anxiety disorders (Wang et al. 2005). The literature points strongly to the value of early diagnosis and intervention in delaying and preventing symptom progression (Davison et al. 2009; Parmelee et al. 1992). Enlisting allied health professionals, such as audiologists, to assist with early detection, support, and triage for mental health concerns has the potential to facilitate early intervention goals and improve client care. The concept of upskilling allied health professionals to detect mental health symptoms and refer possible cases to GPs and/or mental health practitioners for diagnosis and treatment has proven beneficial in school-based screening for mental health conditions in adolescents (Kuo et al. 2009; Vander Stoep et al. 2005), and postnatal 
depression screening conducted by child health nurses (Jones et al. 2012; Leigh and Milgrom 2008). Given that audiologists currently discuss the impact of hearing loss on personal relationships, social interactions and quality of life during audiological rehabilitation, there is significant potential for audiologists to enhance the lives of the clients they work with through provision of emotional support, including recognising the signs of emotional and/or psychological symptoms and connecting people to appropriate services.

It is therefore important to understand how audiologists currently recognise and respond to emotional and psychological concerns and/or symptoms raised during audiology appointments. The aims of this study were:

1) To identify audiologists' self-reported usual response when clients present with emotional and psychological concerns and/or symptoms in the audiological setting.

2) To investigate audiologists' ability to identify and describe psychological symptoms.

3) To explore audiologists' self-reported clinical behaviours relating to client referral for psychological support.

\section{METHODS}

The vignettes under investigation in this study were included in a larger survey that aimed to explore audiologists' knowledge, beliefs and practices relating to mental health. The methodology of the larger survey has been reported in detail elsewhere (Bennett et al. 2020) and is described briefly below. Reported here are the participants descriptions of their self-reported clinical behaviours in response to three case vignettes (hypothetical 
scenarios), a methodology frequently used in mental health research (Hughes and Huby 2002; Winsor and McLean 2016).

\section{Ethical Considerations}

Ethical approval for this study was granted by the Human Research Ethics Committee of The University of Western Australia and The University of Queensland's Human Research Ethics Committee.

\section{Participants}

Participants were eligible to participate in the study if they were audiologists currently practising in Australia. There were no exclusion criteria in terms of years of experience, area of clinical speciality, or place of employment. Participants were recruited at a series of audiology training workshops conducted by the audiology peak body in Australia (Audiology Australia) in Perth (Western Australia), Adelaide (South Australia) and Hobart (Tasmania) in November 2017. Additionally, an invitation to participate in the study was advertised in the quarterly electronic magazine emailed to all members of Audiology Australia in the same month as the workshops.

\section{Materials}

The vignettes under investigation in this study, were included in a larger survey that aimed to explore audiologists' knowledge, beliefs and practices relating to mental health. A 22-item survey using open and closed-ended questions was developed based on previously published surveys used to evaluate knowledge, beliefs and practices of nurses and speechlanguage pathologists in addressing clients' mental health needs during routine clinical care 
(Davison et al., 2009; Northcott et al., 2017; Sekhon et al., 2015). The survey comprised three sections: (1) demographic and professional questions; (2) three case vignettes to explore symptom-management activities; and (3) questions investigating knowledge, beliefs and practices of audiologists in addressing the emotional and mental health needs of adults with hearing loss. The closed-response items are reported in Bennett et al. (2020), and the responses to the vignettes are reported herein.

Three case vignettes were developed to explore how audiologists perceive themselves to be responding to clients presenting with emotional and psychological concerns and/or symptoms in the clinical setting (Appendix One). Two of the vignettes described clients with clinical depression based on the DSM-V criteria (American Psychiatric Association 2013) (Cases One and Three) and one control vignette presented with signs of grief and loneliness (Case Two). In developing the case vignettes, consideration was given to the following factors: that (1) symptoms described in the two vignettes presenting with psychiatric illness fulfilled the DSM-V criteria (American Psychiatric Association 2013), while the symptoms described in the control vignette did not; (2) all symptoms described are consistent with those sometimes presented during audiology consultations; (3) all provided a similar amount of information from which the participating audiologist could make their clinical decisions; and (4) all three vignettes were presented as female clients to control for possible influences of gender. All three vignettes were subject to review by four mental health consultants and five clinical audiologists to ensure the ecological validity of the behaviour depicted in the scenarios.

Participants were asked to answer three questions in relation to each of the three vignettes presented. The cases were presented as "We are interested in learning more about how audiologists respond when clients report experiences associated with emotional 
well-being. Please read the three cases below and let us know what you would normally do during a clinical consultation by completing the questions provided for each case"

a) Respondents were asked to describe their usual course of action if presented with a case like this in their clinical environment.

b) Respondents were asked to indicate whether the symptoms described were consistent with a mental illness, and to report how they would describe the symptoms in a report to a GP or mental health professional.

c) Respondents were asked to indicate whether they would recommend their client seek help beyond the audiologist for their presenting concerns and if so, from who.

\section{Procedure}

All workshop attendees received a printed copy of the survey (including a URL to an electronic version) and were invited to participate by completing the survey in hardcopy or electronically. Attendees who chose to complete the hardcopy version of the questionnaire were asked to leave it in a box provided to ensure anonymity of responses. Individuals who responded to the advertisement in the online magazine were instructed to click on a link to an electronic version of the survey. The survey took approximately 20 minutes to complete.

\section{Data analysis}

Survey data were entered into Microsoft Excel for analysis. To identify audiologists' self-reported usual response when clients present with emotional and psychological concerns and/or symptoms in the audiological setting (aim 1), participant responses to 
question (a) were investigated in two ways. First, the responses were tabulated as actions addressing the (i) audiological, (ii) emotional/psychological, (iii) audiological and emotional/psychological, or (iv) neither audiological nor emotional/psychological symptoms described in the vignettes. Second, the raw responses to question (a) were analysed using content analysis (Graneheim and Lundman 2004). This qualitative analysis involved: reading and clarifying participants' answers to survey questions; identifying meaning units within the data (identifying individual words/phrases within the data, yet still retaining their original meaning and context); coding meaning units by grouping together those most closely related; and grouping coded meaning units into categories. Peer debriefing was used to improve the rigour of the qualitative content analysis. One author completed the initial content analysis (RB). Two other members of the research team ( $C M$ \& BR) then crosschecked all of the analysed data to strengthen the accuracy of the coding. The three researchers ( $R B, C M \& B R$ ) discussed discrepancies and $R B$ reviewed the entire data set in line with the groups' comments. This process was then repeated once more. Categories and meaning units were tabulated, with the number of participants contributing to each meaning unit provided. To identify the emotional support provided by audiologists during clinical consultations, the raw meaning units that described the provision of emotional support from the content analysis were tabulated across the three vignettes.

To investigate audiologists' ability to identify and describe psychological symptoms (aim 2), participant responses to question (b) were tabulated according to whether or not the audiologist indicated that the symptoms described in the vignette were consistent with a mental health problem. The participants' descriptions of the symptoms presented in the vignettes when reporting them to a GP or mental health professional (MHP) were tabulated and classified as (i) consistent with the vignette, or (ii) inconsistent with the vignette 
(including interpretations of the symptoms provided). This analysis was conducted by RB and cross checked by BL.

To explore audiologists' self-reported clinical behaviours relating to referral (aim 3), participant responses to question (c) were tabulated according to whether or not they would recommend the cases described in the vignettes seek further help for their mental health concerns. The types of referrals described in the open ended responses were explored.

\section{RESULTS}

Although 95 audiologists participated in the larger study investigating the mental health knowledge, beliefs and self-report practices of Australian audiologists (Bennett et al. 2020), only 83 provided responses to the case vignettes. There was no statistically significant differences between the two cohorts' age and gender distributions. This subcohort who completed the case vignettes included audiologists from all Australian states and territories and all specialities (i.e., paediatric, tinnitus, diagnostic, vestibular, adult rehabilitation and cochlear implants). Of those who responded to the vignettes, $81 \%$ ( $n=$ 67 indicated that they or someone close to them had experienced mental health concerns, $13 \%(n=11)$ had no experience with mental health, and $6 \%(n=5)$ did not respond to the question. Twenty-seven respondents (33\%) indicated that they routinely ask audiology clients whether they are concerned about their mental well-being or whether they have recently experienced anxiety, depression or suicidal thoughts. Sixty-eight respondents (82\%) indicated having received training in delivering basic counselling techniques. Seventy-four 
respondents (96\%) indicated that they would be interested in developing their knowledge and skills associated with mental health and emotional well-being.

What is an audiologists' self-reported usual response when clients present with emotional and psychological concerns and/or symptoms in the audiological setting?

More than half of the audiologists described actions that addressed both the audiological and emotional/psychological symptoms for Cases One (61\%) and Two (56\%), as did $46 \%$ of participants for Case Three (Table 1). The rest of the audiologists described actions that addressed only the audiological content, and none described only emotional/psychological actions. Participants described a wide range of clinical behaviours in response to each of the three case studies (Case One: $n=331$, Case Two: $n=273$, Case Three: $n=221$, individual meaning units provided in Appendix 2). The main themes that emerged following analysis of the audiologists' descriptions of their normal course of action included: Informational counselling, Diagnostic testing, Interventions (including hearing aids, assistive listening devices and communication training), Clinical processes, Emotional support, Involving or referral to external help (including professional and community services), Imposing the clinician's views onto the client, and the Clinician is unsure what to do (Appendix 2). The theme Clinical Processes described modifications to the normal audiological rehabilitation process, such as delaying audiological rehabilitative care to focus on psychosocial/psychological concerns, slowing down the appointment, and making time for non-audiological discussion. The theme Emotional support included 28 different approaches, across ten sub-themes (Appendix 2); however, for the most part, participants that did describe provision of emotional support only described one or two approaches each. The most commonly reported approach to provision of emotional support was Active 
Listening, followed by Provision of Emotional Based Counselling, and Acknowledging and Validating Feelings. Participants described a greater provision of emotional support and counselling approaches in response to the control vignette (describing grief), than in response to the vignettes describing symptoms of depression.

\section{Audiologists' identification of psychological symptoms}

Participating audiologists were asked whether the client depicted in each case had symptoms consistent with a mental health problem. They were not asked to specify which mental health disorder, only to indicate if they felt there was an underlying mental health disorder. For the two cases describing symptoms consistent with depression, $96 \%(n=80)$ and $63 \%(n=52)$ of participants indicated that they believed the symptoms presented in Case One and Case Three (respectively) were consistent with a mental health disorder. For Case Two (grief but no mental health disorder consistent with the DSM-V) $48 \%$ of participants indicated that they believed the symptoms were consistent with a mental health disorder. Participating audiologists were asked to report how they would describe the symptoms in a report to a GP or mental health professional. Participants described 31 different symptoms for Case One, 14 for Case Two, and 18 for Case Three (Table 2). In 40\% of cases (Case One: $49 \%$, Case Two: $25 \%$, Case Three: $36 \%$ ), participants used words to describe symptoms that differed from the words provided in the case vignettes.

\section{Audiologists' self-reported clinical behaviours relating to client referral for psychological support}

Participants were asked whether they would recommend the client depicted in each case study seek help beyond audiological services, and if so, to describe who they would 
refer to. The majority of participants indicated they would recommend these cases seek further help for their mental health concerns (Case One: $94 \%, n=78$; Case Two: $80 \%, n=66$; Case Three: 72\%, $n=60$ ). Participants' listed 25 different referral points, with GPs and mental health practitioners most frequently recommended (Table 3).

\section{DISCUSSION}

This study investigated audiologists' self-reported clinical response to emotional and psychological concerns raised by clients in the audiological setting. There was a divide between clinical practices with just over half of the audiologists participating in this study describing clinical actions that addressed the emotional and psychological symptoms described. Few audiologists described referral as part of routine care for the cases with depression, and where referral was described, audiologists often described referral pathways inconsistent with guidelines recommending GPs as central to mental health care plans. Our findings suggest that audiologists are not adequately detecting, addressing and referring for poor psychological wellbeing, including cases that are consistent with a DSM-V diagnosis.

A vital first step in the delivery of mental health support is the ability to detect psychological distress and address an individual's needs in terms of their distress. The American Speech and Language Association's Scope of Practice for audiologists describes the role of the audiologist as including use of "screening measures of mental health" to assist with the assessment, treatment and referral of mental health concerns (American Speech-Language-Hearing Association 2018). However, when describing their usual course of action in response to the vignettes, only one of the audiologists participating in the 
current study described the use of mental health screening tools to assist with symptom identification. Despite suspicions regarding the presence of a mental health condition, it appears that Australian audiologists are not using screening tools to assist with symptom identification and client management. In line with American guidelines, updating Australian guidelines to include the use of mental health screening tools may assist audiologists to improve their mental health detection and management practices.

Over half of the audiologists participating in this study described the provision of emotional support to address the emotional and/or psychological concerns raised in the vignettes. These practices align with clinical guidelines describing the role of the audiologist in addressing the social, psychosocial and psychological needs of clients during the process of audiological rehabilitation (American Speech-Language-Hearing Association 2018; Audiology Australia 2013). Scott and Barton (2010) define emotional support (emotionfocussed counselling) as monitoring a person's psychological well-being, providing accessible information, and emotional care, such as acknowledging distress and anxiety, and listening with empathy. They argue that emotional support should be a routine and integral part of caring for all clients in the healthcare setting. This notion is echoed by English (2008), describing the role of the audiologist in providing "personal adjustment counselling", that is, responding to the affective component in clients' dialogue. Although collectively, participants in the current study described a wide range of approaches to providing emotional support, on an individual basis, there was little depth of skill described, with participants often listing only one or two approaches each, rather than describing a range of support methods. This may suggest that audiologists do not provide comprehensive emotional support, as observed by others (Ekberg et al. 2014; Grenness et al. 2015). A 
recent international Delphi study identified 64 counselling competencies considered important for audiologists to possess to provide effective counselling in practice (16 knowledge, 35 skills, and 13 attitudinal items) (Meibos 2018). There was significant overlap between the competencies raised by Meibos (2018) and those described by participants in the current study. The wide range of approaches to providing emotional support during audiology consultations identified by Meibos (2018) and by the participants in this study highlight the multifaceted ways in which emotional support can be delivered by audiologists in the clinical setting to address the mental health needs of adults with hearing loss.

When asked how they would describe the symptoms presented in the case vignettes if reporting to a GP, participants most frequently used the same language and descriptions provided in the case vignettes. Some participants correctly interpreted the symptoms and described a mental health disorder. Regarding Case One (depression), $45 \%(n=31)$ of participants used the term "depression" when describing the symptoms. While this is correct "labelling" of the condition, audiologists are not trained in the diagnosis of mental health disorders, nor is it within their scope of practice, and thus audiologists should exercise caution, or avoid, labelling a condition. An example of where "labelling" can be problematic, can be demonstrated by participants responses to Case Two (the control vignette, describing a client experiencing grief and symptoms that are not consistent with a mental health disorder according to the DSM5). Seven percent $(n=6)$ of participants indicated that they would describe this clients symptoms as "depression" when writing to her GP. The potential impact of labelling and misdiagnosis on the client and their treatment pathway is not fully understood. Although some studies suggest that psychiatric labelling can support early recognition of mental disorders and therefore assist early diagnosis and 
treatment (Wang et al., 2005; Wright, Jorm, Harris, \& McGorry, 2007), others suggest that it can also lead to self-stigmatisation and reluctance to seek psychotherapy (Xu et al., 2016), and in some cases, social distancing and discrimination towards those suffering from mental disorders (Angermeyer \& Matschinger, 2005). It is therefore important for audiologists to understand labelling, and to discuss symptoms using the words and phrases that the client has used to describe their condition. Additionally, use of screening tools may assist with both symptom detection and correct labelling for referral purposes.

When asked directly, the majority of participants in the current study indicated that they would refer the three vignettes for specialist support; however, less than one third described referral to a GP and less than $5 \%$ described referral to a mental health professional as their normal course of action in the open response item. This inconsistency between intended actions and described actions may be influenced by response bias (further described below) and/or uncertainty regarding pathways and responsibilities in caring for people with mental health disorders, possibly due to a lack of national guidelines (Australian Medical Association 2018).

\section{Clinical Implications}

Use of clinical pathways providing evidence-based recommendations to guide best practice have been shown to significantly increase detection of mental health disorders and rates of referral for treatment (Ski et al. 2015). Recent guidelines developed to assist cardiac, stroke and oncology nurses have employed a stepped-care approach to managing mental health conditions (Kneebone 2016; Butow et al. 2015; Tully and Baumeister 2014). The aim of stepped-care models is to maximize access to appropriate care while making the 
best use of available resources for psychological support (Haaga 2000). Where some clients may receive sufficient help through self-help information (Anderson et al. 2005; Cuijpers et al. 2010), learning relaxation techniques (Jorm et al. 2008), or joining support groups (Griffiths et al. 2012; Houston et al. 2002), others may require long-term treatment from highly trained psychotherapists (Cuijpers et al. 2008; de Mello et al. 2005; Pinquart, Duberstein and Lyness 2007), or use of antipsychotics (Coupland et al. 2011). In the stepped-care approach, lower cost and less restrictive interventions are tried first, with more intensive and costly interventions reserved for those insufficiently helped by the initial interventions. A key benefit of the stepped-care approach is that it can be delivered by professionals that do not have psychotherapeutic training, with successful implementation demonstrated with GPs (Thielke et al. 2007), speech pathologists (Ryan et al. 2017), and school teachers (Domitrovich et al. 2010). Development of clinical pathways employing a stepped-care approach could provide a clinical and economic solution to addressing mental health in the audiology setting.

\section{Limitations and future research}

One limitation of research via self-selecting survey is the effects of response bias. Although we estimate that around 3\% of all Australian audiologists participated in the study and that there was a mixed sample with regards to age, gender, years of experience, place of employment, and area of clinical speciality, participants self-selected to participate. It is likely that the clinicians most interested in mental health would be inclined to complete the survey.

Participants were aware that the purpose of the study was to explore audiologists' provision of emotional and mental health support in audiological practice. This was 
necessary as our ethical obligation required that participants were aware of the studies aims and provided informed consent prior to participating. The results may overestimate how clinicians respond to symptoms of poor psychological well-being due to social desirability response bias; that is, the tendency for participants to present a favourable image of themselves (van de Mortel, 2008). Response biases of this nature may have been mitigated by the anonymity of the survey, giving respondents freedom to raise controversial viewpoints or acknowledge clinical weaknesses that they might avoid disclosing in front of peers. Additionally, although we intentionally placed the open-response questions exploring clinical behaviours before the closed-response questions, it is possible that participants may have amended their open-response text after reading the subsequent questions. Future research may present vignettes and closed-response questions in two separate studies so as not to bias responses to the vignettes. Nonetheless, this self-report survey methodology enabled us to canvas a broad range of views and provide direction for future research. A more general limitation of this survey methodology is that responses cannot be further explored. For example, participants might have provided further details regarding the range of counselling approaches used if prompted. Furthermore, participants self-reported their clinical behaviours relating to mental health management and so we do not know what is actually happening during clinical encounters. Finally, this study included only audiologists (university trained) working in Australia, whereas hearing services in Australia are provided by both audiologists and audiometrists (non-university trained), and the training undertaken by each professional group varies. Further research is needed to better understand the receipt of mental health support by clients in the broader audiology setting.

Although cohort and population studies have used screening tools to estimate depression and mental health status (Dawes et al. 2015; Jayakody et al. 2018; Keidser and 
Seeto 2017), few studies have investigated the use of mental health screening questionnaires in audiological practice (Zöger et al. 2004). Thus the validity of mental health screening tools for use in populations of adults with hearing loss is unknown. The importance of checking the validity of tools for use in sub-populations, such as adults with hearing loss, was demonstrated by Dupuis et al. (Dupuis et al. 2014). They found that participants with more severe hearing loss more often failed short term memory tasks as they were unable to repeat and then recall words delivered verbally during assessment, suggesting that use of a verbal assessment for cognitive function will falsely inflate rates of cognitive decline for adults with hearing loss. It is possible that the same could be true for measures of mental health that include items assessing situations that require hearing and aural communication. While the appropriateness of the survey for use with the client population is vitally important, so too is the appropriateness of the survey for use by the administrator. Some suggest that measures of depression and anxiety may not all be appropriate for use in the clinical setting, or by professionals not trained in psychotherapeutic approaches due to the "negative language" or jargon used (Hammond 2004; Jongenelis et al. 2007). Further research is needed to understand which, if any, existing mental health screening tools are appropriate for use with adults with hearing loss, and by audiologists.

\section{Conclusions}

Compared to GPs and clinical psychologists, audiologists are not trained or qualified to provide diagnosis or therapeutic interventions for mental health disorders. However, audiologists do play a vital role in contributing to the holistic health of their clients, and therefore have a clinical responsibility to ensure they are sufficiently trained to identify 
psychological symptoms, lead discussions with their clients about their mental health, and refer clients to their GP or local mental health professionals. Findings from this study suggest that approximately half of clinical audiologists are meeting these requirements through use of a diverse range of clinical approaches when providing emotional support. Furthermore, audiologists appear to modify and personalise clinical processes when mental health symptoms are detected. These modifications include slowing down the appointment, delaying audiological rehabilitation decision making, making space to discuss nonaudiological content, and involving significant others. Finally, audiologists demonstrated a lack of knowledge regarding who, when and how to refer clients for psychological support, indicating a need for targeted training improving audiologists' mental health referral patterns.

\section{Acknowledgements}

The authors would like to thank Audiology Australia for assisting with participant recruitment and participants for their time. The authors would like to thank the Ear Science Institute Australia for funding this project. The authors report no conflicts of interest. Portions of this article were presented at the Audiology Australia webinar "Mental Health and Hearing Loss", September, 2019.

\section{References}

American Speech-Language-Hearing Association. (2018). Scope of Practice in Audiology. Retrieved from https://www.asha.org/policy/sp2018-00353/ 
Anderson, L., Lewis, G., Araya, R., Elgie, R., Harrison, G., Proudfoot, J., ... Williams, C. (2005). Selfhelp books for depression: how can practitioners and patients make the right choice? Brittish Journal of General Practice, 55(514), 387-392.

Angermeyer, M. C., \& Matschinger, H. (2005). Labeling-stereotype-discrimination. Social Psychiatry and Psychiatric Epidemiology, 40(5), 391-395.

American Psychiatric Association (2013). Diagnostic and statistical manual of mental disorders (DSM$\left.5^{\circledR}\right)$ : American Psychiatric Association Publication.

Audiology Australia (2013). "Audiology Australia Professional Practice Standards." Retrieved 4th June 2018, from http://audiology.asn.au/index.cfm/resources-publications/professionalresources/professional-practice-standards/.

Australian Bureau of Statistics. (2008). National Survey of Mental Health and Wellbeing: Summary of Results, 2007. Cat. no. (4326.0). Canberra: ABS

Australian Medical Association. (2018). Position Statement: Mental Health - 2018 [Press release]. Retrieved from https://ama.com.au/position-statement/mental-health-2018

Barker, A. B., Leighton, P. \& Ferguson, M. A. (2017). Coping together with hearing loss: a qualitative meta-synthesis of the psychosocial experiences of people with hearing loss and their communication partners. International Journal of Audiology, 56(5), 297-305.

Bennett, R. J., Meyer, C. J., Ryan, B., Lawrence, B. J., Barr, C., Laird, E. \& Eikelboom, R. H. (2020). Knowledge, beliefs and practices of Australian audiologists in addressing the psychological needs of adults with hearing loss. American Journal of Audiology - Accepted January 2020.

Butow, P., Price, M. A., Shaw, J. M., Turner, J., Clayton, J. M., Grimison, P., . . Kirsten, L. (2015). Clinical pathway for the screening, assessment and management of anxiety and depression in adult cancer patients: Australian guidelines. Psycho-Oncology, 24(9), 987-1001.

Coupland, C., Dhiman, P., Morriss, R., Arthur, A., Barton, G. \& Hippisley-Cox, J. (2011). Antidepressant use and risk of adverse outcomes in older people: population based cohort study. Brittish Medical Journal, 343, d4551. 
Cuijpers, P., Donker, T., van Straten, A., Li, J. \& Andersson, G. (2010). Is guided self-help as effective as face-to-face psychotherapy for depression and anxiety disorders? A systematic review and meta-analysis of comparative outcome studies. Psychological Medicine, 40(12), 19431957.

Cuijpers, P., van Straten, A., Andersson, G. \& van Oppen, P. (2008). Psychotherapy for depression in adults: a meta-analysis of comparative outcome studies. Journal of Consulting and Clinical Psychology, 76(6), 909.

Davison, T. E., McCabe, M. P., Mellor, D., Karantzas, G. \& George, K. (2009). Knowledge of late-life depression: an empirical investigation of aged care staff. Aging and Mental Health, 13(4), 577-586.

Dawes, P., Emsley, R., Cruickshanks, K. J., Moore, D. R., Fortnum, H., Edmondson-Jones, M., . . . Munro, K. J. (2015). Hearing loss and cognition: the role of hearing AIDS, social isolation and depression. PLoS One, 10(3), e0119616.

Davison, T. E., McCabe, M. P., Mellor, D., Karantzas, G., \& George, K. (2009). Knowledge of late-life depression: an empirical investigation of aged care staff. Aging and Mental Health, 13(4), $577-586$.

de Mello, M. F., de Jesus Mari, J., Bacaltchuk, J., Verdeli, H. \& Neugebauer, R. (2005). A systematic review of research findings on the efficacy of interpersonal therapy for depressive disorders. European Archives of Psychiatry and Clinical Neuroscience, 255(2), 75-82.

Domitrovich, C. E., Bradshaw, C. P., Greenberg, M. T., Embry, D., Poduska, J. M. \& Ialongo, N. S. (2010). Integrated models of school-based prevention: Logic and theory. Psychology in the Schools, 47(1), 71-88.

Dupuis, K., Pichora-Fuller, M. K., Chasteen, A. L., Marchuk, V., Singh, G. \& Smith, S. L. (2014). Effects of hearing and vision impairments on the Montreal Cognitive Assessment. Aging, Neuropsychology, and Cognition, 1-25. 
Ekberg, K., Grenness, C. \& Hickson, L. (2014). Addressing patients' psychosocial concerns regarding hearing aids within audiology appointments for older adults. American Journal of Audiology, 23(3), 337-350.

English, K. (2008). Counseling issues in audiologic rehabilitation. Contemporary Issues in Communication Science, 35, 93-101.

Fiske, A., Wetherell, J. L. \& Gatz, M. (2009). Depression in older adults. Annual Review of Clinical Psychology, 5, 363-389.

Graneheim, U. H. \& Lundman, B. (2004). Qualitative content analysis in nursing research: concepts, procedures and measures to achieve trustworthiness. Nurse Education Today, 24(2), 105112.

Grenness, C., Hickson, L., Laplante-Lévesque, A., Meyer, C. \& Davidson, B. (2015). The nature of communication throughout diagnosis and management planning in initial audiologic rehabilitation consultations. Journal of the American Academy of Audiology, 26(1), 36-50.

Griffiths, K. M., Mackinnon, A. J., Crisp, D. A., Christensen, H., Bennett, K. \& Farrer, L. (2012). The effectiveness of an online support group for members of the community with depression: a randomised controlled trial. PLoS One, 7(12), e53244.

Haaga, D. A. (2000). Introduction to the special section on stepped care models in psychotherapy. Journal of Consulting and Clinical Psychology, 68(4), 547.

Hammond, M. F. (2004). Doctors' and nurses' observations on the Geriatric Depression Rating Scale. Age Ageing, 33(2), 189-192.

Han, J., Lee, H., Jung, J. \& Park, E.-C. (2018). Effects of self-reported hearing or vision impairment on depressive symptoms: a population-based longitudinal study. Epidemiology and Psychiatric Sciences, 1-13.

Hilton, M. F., Scuffham, P. A., Vecchio, N. \& Whiteford, H. A. (2010). Using the interaction of mental health symptoms and treatment status to estimate lost employee productivity. Australian and New Zealand Journal of Psychiatry, 44(2), 151-161. 
Hogan, A., O'Loughlin, K., Miller, P. \& Kendig, H. (2009). The health impact of a hearing disability on older people in Australia. Journal of Aging and Health, 21(8), 1098-1111.

Houston, T. K., Cooper, L. A. \& Ford, D. E. (2002). Internet support groups for depression: a 1-year prospective cohort study. American Journal of Psychiatry, 159(12), 2062-2068.

Huang, C.-Q., Dong, B.-R., Lu, Z.-C., Yue, J.-R. \& Liu, Q.-X. (2010). Chronic diseases and risk for depression in old age: a meta-analysis of published literature. Ageing Research Reviews, 9(2), 131-141.

Hughes, R. \& Huby, M. (2002). The application of vignettes in social and nursing research. Journal of Advanced Nursing, 37(4), 382-386.

Jayakody, D. M., Almeida, O. P., Speelman, C. P., Bennett, R. J., Moyle, T. C., Yiannos, J. M. \& Friedland, P. L. (2018). Association between speech and high-frequency hearing loss and depression, anxiety and stress in older adults. Maturitas, 110, 86-91.

Jones, C. J., Creedy, D. K. \& Gamble, J. A. (2012). Australian midwives' awareness and management of antenatal and postpartum depression. Women and Birth, 25(1), 23-28.

Jongenelis, K., Gerritsen, D., Pot, A., Beekman, A., Eisses, A., Kluiter, H. \& Ribbe, M. (2007). Construction and validation of a patient-and user-friendly nursing home version of the Geriatric Depression Scale. International Journal of Geriatric Psychiatry: A journal of the psychiatry of late life and allied sciences, 22(9), 837-842.

Jorm, A. F., Morgan, A. J. \& Hetrick, S. E. (2008). Relaxation for depression. Cochrane Database of Systematic Reviews(4).

Keidser, G. \& Seeto, M. (2017). The influence of social interaction and physical health on the association between hearing and depression with age and gender. Trends in Hearing, 21, 115.

Kneebone, I. I. (2016). Stepped psychological care after stroke. Disability and Rehabilitation, 38(18), 1836. 
Kuo, E., Stoep, A. V., McCauley, E. \& Kernic, M. A. (2009). Cost-effectiveness of a school-based emotional health screening program. Journal of School Health, 79(6), 277-285.

Laplagne, P., Glover, M. \& Shomos, A. (2007). Effects of health and education on labour force participation. Available at SSRN 1018889 (2007).

Lawrence, B. J., Jayakody, D. M., Eikelboom, R. H., Bennett, R. J., Gasson, N. \& Friedland, P. L. (2019). Age-related hearing loss and depression in older adults: A systematic review and metaanalysis. The Gerontologist - In Press.

Lebowitz, B. D., Pearson, J. L., Schneider, L. S., Reynolds, C. F., Alexopoulos, G. S., Bruce, M. L., . . Morrison, M. F. (1997). Diagnosis and treatment of depression in late life: consensus statement update. Jama, 278(14), 1186-1190.

Leigh, B. \& Milgrom, J. (2008). Risk factors for antenatal depression, postnatal depression and parenting stress. BMC psychiatry, 8(1), 24.

Li, C.-M., Zhang, X., Hoffman, H. J., Cotch, M. F., Themann, C. L. \& Wilson, M. R. (2014). Hearing impairment associated with depression in US adults, National Health and Nutrition Examination Survey 2005-2010. JAMA Otolaryngology-Head \& Neck Surgery, 140(4), 293302.

Meibos, A. R. (2018). PhD thesis. Counseling Competencies in Audiology: Important Knowledge, Skills, and Attitudes. Utah State University, Retrieved from https://digitalcommons.usu.edu/etd/7087

Mokdad, A. H., Ballestros, K., Echko, M., Glenn, S., Olsen, H. E., Mullany, E., .. F Ferrari, A. J. (2018). The state of US health, 1990-2016: burden of diseases, injuries, and risk factors among US states. Jama, 319(14), 1444-1472.

Parmelee, P. A., Katz, I. R. \& Lawton, M. P. (1992). Depression among institutionalized aged: assessment and prevalence estimation. Journal of Gerontology, 44(1), M22-M29.

Parslow, R. A., Lewis, V. \& Marsh, G. (2011). The general practitioner's role in providing mental health services to Australians, 1997 and 2007: Findings from the national surveys of mental 
health and wellbeing-Research-In a decade of increasing access, did GPs take up the mantle? Medical Journal of Australia, 195(4), 205.

Pearson, S. D., Katzelnick, D. J., Simon, G. E., Manning, W. G., Helstad, C. P. \& Henk, H. J. (1999). Depression among high utilizers of medical care. Journal of General Internal Medicine, 14(8), 461-468.

Penninx, B. W., Deeg, D. J., van Eijk, J. T. M., Beekman, A. T. \& Guralnik, J. M. (2000). Changes in depression and physical decline in older adults: a longitudinal perspective. Journal of Affective Disorders, 61(1-2), 1-12.

Pinquart, M., Duberstein, P. \& Lyness, J. (2007). Effects of psychotherapy and other behavioral interventions on clinically depressed older adults: a meta-analysis. Aging and Mental Health, 11(6), 645-657.

Pronk, M., Deeg, D. J., Smits, C., Twisk, J. W., van Tilburg, T. G., Festen, J. M. \& Kramer, S. E. (2014). Hearing loss in older persons: does the rate of decline affect psychosocial health? Journal of Aging and Health, 26, 703-723.

Reynolds, K., Pietrzak, R. H., El-Gabalawy, R., Mackenzie, C. S., \& Sareen, J. (2015). Prevalence of psychiatric disorders in US older adults: findings from a nationally representative survey. World Psychiatry, 14(1), 74-81.

Ryan, B., Hudson, K., Worrall, L., Simmons-Mackie, N., Thomas, E., Finch, E., . . Lethlean, J. (2017). The Aphasia Action, Success, and Knowledge Programme: Results from an Australian Phase I Trial of a Speech-Pathology-Led Intervention for People with Aphasia Early Post Stroke. Brain Impairment, 18(3), 284-298.

Sekhon, J. K., Douglas, J., \& Rose, M. L. (2015). Current Australian speech-language pathology practice in addressing psychological well-being in people with aphasia after stroke. International Journal of Speech-Language Pathology, 17(3), 252-262.

Scott, S. \& Barton, J. (2010). Psychological approaches to working with people in the early stages of recovery. Psychological well-being and acquired communication impairments, 156-174. 
Simning, A., Fox, M. L., Barnett, S. L., Sorensen, S. \& Conwell, Y. (2018). Depressive and Anxiety Symptoms in Older Adults With Auditory, Vision, and Dual Sensory Impairment. Journal of Aging and Health, 31(8): 1353-1375.

Ski, C. F., Munian, S., Rolley, J. X. \& Thompson, D. R. (2015). Evaluation of nurses' perceptions of the impact of targeted depression education and a screening and referral tool in an acute cardiac setting. Journal of Clinical Nursing, 24(1-2), 235-243.

Thielke, S., Vannoy, S. \& Unützer, J. (2007). Integrating mental health and primary care. Primary care: Clinics in office practice, 34(3), 571-592.

Tully, P. J. \& Baumeister, H. (2014). Collaborative care for the treatment of comorbid depression and coronary heart disease: a systematic review and meta-analysis protocol. Systematic Reviews, 3(1), 127.

van de Mortel, T. F. (2008). Faking it: social desirability response bias in self-report research. The Australian Journal of Advanced Nursing, 25(4), 40.

Vander Stoep, A., Mccauley, E., Thompson, K. A., Herting, J. R., Kuo, E. S., Stewart, D. G., . . Kushner, S. (2005). Universal emotional health screening at the middle school transition. Journal of Emotional and Behavioral Disorders, 13(4), 213-223.

Wang, P. S., Berglund, P., Olfson, M., Pincus, H. A., Wells, K. B. \& Kessler, R. C. (2005). Failure and delay in initial treatment contact after first onset of mental disorders in the National Comorbidity Survey Replication. Archives of General Psychiatry, 62(6), 603-613.

West, J. S. (2017). Hearing impairment, social support, and depressive symptoms among US adults: A test of the stress process paradigm. Social Science and Medicine, 192, 94-101.

Wilkinson, P. \& Izmeth, Z. (2012). Continuation and maintenance treatments for depression in older people. Cochrane Database of Systematic Reviews(11).

Winsor, T. \& McLean, S. (2016). Residential group care workers' recognition of depression: Assessment of mental health literacy using clinical vignettes. Children and Youth Services Review, 68, 132-138. 
Wright, A., Jorm, A. F., Harris, M. G., \& McGorry, P. D. (2007). What's in a name? Is accurate recognition and labelling of mental disorders by young people associated with better helpseeking and treatment preferences? Social Psychiatry and Psychiatric Epidemiology, 42(3), 244-250.

World Health Organization. (2008). Global Burden of Disease (2008): 2004 update. Retrieved from http://www.who.int/healthinfo/global burden disease/GBD report 2004update full.pdf World Health Organization. (2017). Deafness and Hearing Loss. Retrieved from http://www.who.int/mediacentre/factsheets/fs300/en/

Xu, Z., Müller, M., Heekeren, K., Theodoridou, A., Dvorsky, D., Metzler, S., ... \& Rüsch, N. (2016). Selflabelling and stigma as predictors of attitudes towards help-seeking among people at risk of psychosis: 1-year follow-up. European Archives of Psychiatry and Clinical Neuroscience, 266(1), 79-82.

Zöger, S., Svedlund, J. \& Holgers, K.-M. (2004). The Hospital Anxiety and Depression Scale (HAD) as a screening instrument in tinnitus evaluation. International Journal of Audiology, 43(8), 458464. 
Table 1. Percentage of participants that reported actions that recognise or address the audiological and/or emotional/psychological symptoms described in the cases $(n=83)$.

\begin{tabular}{lccc}
\hline $\begin{array}{l}\text { Number of participants that reported actions } \\
\text { that... }\end{array}$ & $\begin{array}{c}\text { Case One: } \\
\text { Depression }\end{array}$ & $\begin{array}{c}\text { Case Two: } \\
\text { Grief }\end{array}$ & $\begin{array}{c}\text { Case Three: } \\
\text { Depression }\end{array}$ \\
\hline $\begin{array}{l}\text { Recognised or addressed audiological symptoms } \\
\text { and NOT emotional/psychological symptoms }\end{array}$ & $33 \%(n=27)$ & $43 \%(n=34)$ & $53 \%(n=39)$ \\
$\begin{array}{l}\text { Recognised or addressed audiological AND } \\
\text { emotional/psychological symptoms }\end{array}$ & $61 \%(n=50)$ & $56 \%(n=45)$ & $46 \%(n=34)$ \\
$\begin{array}{l}\text { Were non-specific towards addressing the } \\
\text { audiological or emotional/psychological aspects } \\
\text { of the case }\end{array}$ & $6 \%(n=5)$ & $1 \%(n=1)$ & $1 \%(n=1)$ \\
\hline
\end{tabular}


Table 2. Participants' descriptions of the case's symptoms when reporting them to a GP or mental health professional.

\begin{tabular}{|c|c|c|c|c|c|}
\hline \multicolumn{2}{|c|}{ Case One: Depression } & \multicolumn{2}{|l|}{ Case Two: Grief } & \multicolumn{2}{|c|}{ Case Three: Depression } \\
\hline Symptoms & $\begin{array}{c}\text { Number of } \\
\text { participants } \\
\text { labelling the } \\
\text { client's } \\
\text { condition in this } \\
\text { way }\end{array}$ & Symptoms & $\begin{array}{l}\text { Number of } \\
\text { participants } \\
\text { labelling the } \\
\text { client's } \\
\text { condition in } \\
\text { this way }\end{array}$ & Symptoms & $\begin{array}{l}\text { Number of } \\
\text { participants } \\
\text { labelling the } \\
\text { client's } \\
\text { condition in } \\
\text { this way }\end{array}$ \\
\hline Depression & 31 & Grieving & 41 & Social isolation & 31 \\
\hline Social isolation & 27 & Depression & 6 & Depression & 17 \\
\hline $\begin{array}{l}\text { Tiredness } \\
\text { (exhaustion/fatigue/low energy) }\end{array}$ & 19 & Loneliness & 5 & Anxiety (including social anxiety) & 13 \\
\hline $\begin{array}{l}\text { General (non-specific) concerns } \\
\text { for mental well-being }\end{array}$ & 14 & Memory problems & 4 & Insomnia & 10 \\
\hline Insomnia - sleep disturbances & 7 & $\begin{array}{l}\text { Possible dementia (confusion \& } \\
\text { comprehension issues) }\end{array}$ & 2 & Poor appetite & 9 \\
\hline $\begin{array}{l}\text { Suicidal ideation / thoughts of } \\
\text { mortality }\end{array}$ & 7 & Struggling with living alone & 2 & Fatigue / exhaustion / lethargy & 7 \\
\hline $\begin{array}{l}\text { Lack of enjoyment in life } \\
\text { (Anhedonia) }\end{array}$ & 7 & $\begin{array}{l}\text { Difficulties focusing / } \\
\text { concentrating }\end{array}$ & 2 & $\begin{array}{l}\text { Lack of enjoyment in activities } \\
\text { previously enjoyed }\end{array}$ & 6 \\
\hline $\begin{array}{l}\text { Quote the client's words (e.g. } \\
\text { Expressed it would be better if } \\
\text { she didn't wake up) }\end{array}$ & 6 & Highly emotional & 1 & $\begin{array}{l}\text { Low self-esteem / self-worth / } \\
\text { confidence }\end{array}$ & 5 \\
\hline Lack of motivation & 5 & Lack of social support / isolation & 1 & Weight loss & 3 \\
\hline Low mood/affect & 5 & No self-esteem & 1 & $\begin{array}{l}\text { Social withdrawal - caused by } \\
\text { hearing loss }\end{array}$ & 3 \\
\hline Disengagement & 4 & $\begin{array}{l}\text { Difficulty making decisions for } \\
\text { herself }\end{array}$ & 1 & Decreased motivation & 3 \\
\hline No will to live & 3 & $\begin{array}{l}\text { Observed difficulty following a } \\
\text { conversation }\end{array}$ & 1 & Loneliness & 3 \\
\hline
\end{tabular}


Lack of self-worth / low selfesteem

No motivation to proceed with amplification

Loss of interest in engaging with others

Loneliness

Feeling like a burden

Loss of interest in life

Despondent / loss of hope

Looking for someone to confide in

Lack of manual dexterity

Anxious

Apathy

Failure to learn a new task

Feels audiological rehabilitation is

wasted on her

Reduced life expectancy

Reduced regard for continued

wellbeing

Fatigued from medication

Drugs used to cope

Clinician is unsure what to write

in the report

"it could be the ageing process"
3

Feeling helpless

Struggling

2

2

2

2

1

1

1

1

1

1

1

1

1

1

(1)

(1)

1

Socially disengaged

2

Clinician not sure how to describe

it, whether to refer for it

Lack of interest in others

Low mood

Restlessness

"Seems to be a loner"
2

1

1

1

1 
1 Table 3. Who participants reported they would refer the cases described in the vignettes to 2 for additional help

\begin{tabular}{|c|c|c|c|}
\hline \multirow{2}{*}{$\begin{array}{l}\text { Who participants indicated that they would } \\
\text { recommend the case clients seek help from }\end{array}$} & \multicolumn{3}{|c|}{ source for help } \\
\hline & $\begin{array}{l}\text { Case One: } \\
\text { Depression }\end{array}$ & $\begin{array}{l}\text { Case Two: } \\
\text { Grief }\end{array}$ & $\begin{array}{l}\text { Case Three: } \\
\text { Depression }\end{array}$ \\
\hline GP & 52 & 28 & 45 \\
\hline $\begin{array}{l}\text { Mental health practitioner (psychologist / } \\
\text { psychiatrist / counsellor / geriatric psychologist) }\end{array}$ & 26 & 31 & 19 \\
\hline $\begin{array}{l}\text { Carers at Hostel (nurse, manager, doctor, carer, } \\
\text { case worker) }\end{array}$ & 20 & 0 & 0 \\
\hline Family / friend & 13 & 15 & 9 \\
\hline Husband & 0 & 0 & 11 \\
\hline Social worker & 6 & 2 & 1 \\
\hline Church / minister / spiritual guidance & 0 & 8 & 0 \\
\hline $\begin{array}{l}\text { Organisation that assists with social re- } \\
\text { engagement (e.g. Anglicare / Beyond Blue / } \\
\text { volunteer visitors ) }\end{array}$ & 5 & 0 & 0 \\
\hline $\begin{array}{l}\text { Organisation that assists with grief management } \\
\text { (e.g. Grief support groups / Beyond Blue / Solace } \\
\text { Australia) }\end{array}$ & 0 & 4 & 0 \\
\hline Geriatrician or GP specialising in geriatric health & 2 & 0 & 0 \\
\hline Occupational therapist & 2 & 0 & 0 \\
\hline Community nurse & 1 & 0 & 0 \\
\hline Audiologist - schedule follow up support & 1 & 0 & 0 \\
\hline Diversional therapist for social interaction & 1 & 0 & 0 \\
\hline Community/social/support groups & 0 & 2 & 2 \\
\hline Local day centre & 0 & 1 & 0 \\
\hline Aged care related organisation & 0 & 1 & 0 \\
\hline Clinician not sure who to refer to & 0 & 0 & 1 \\
\hline Sleep specialist & 0 & 0 & 1 \\
\hline Marriage counsellor & 0 & 0 & 1 \\
\hline Support group for people with hearing loss & 0 & 0 & 1 \\
\hline Women's mental health support services & 0 & 0 & 1 \\
\hline Allied health coordinator & 0 & 0 & 1 \\
\hline Dietician & 0 & 0 & 1 \\
\hline Clinician is unsure & 2 & 0 & 0 \\
\hline
\end{tabular}


Appendix One. Case vignettes

Case One

"Mrs Ring is a 92 year old widow living in an outer-suburb aged care hostel. She has moderate to severe hearing loss bilaterally and her current hearing aids are now seven years old, though she reports rarely wearing them. She has difficulty hearing the other residents at mealtimes, but isn't so concerned as she prefers to keep to herself. She says that she never has visitors and so has no reason to hear. She says that at her age, she doesn't have much to live for and so is just waiting for her time to be up.

You offer to arrange new hearing aids for her under OHS, but she says not to bother, that she doesn't do anything that requires hearing anymore and that new hearing aids would be wasted on her and the money better spent on someone who would use them. She tells you that she is too tired to learn anything new and that the pills they give her to help her sleep don't seem to be working, so she is just constantly exhausted. She tells you that she thinks it would be easier for everyone if she wasn't to wake up the next morning."

\section{Case Two}

"Mrs Smith is a 67 year old widow with moderate hearing loss bilaterally. She reports being keen to try hearing aids as she often mishears what people say, especially at church, when speaking to her daughters on the phone, and at gardening club. When you ask about hearing around the house, she bursts into tears and says that her husband of 49 years died three weeks ago and that she is struggling to cope with living alone. She thinks about him to the point of tears most days and feels quite lonely. Her daughters try to help, but they are pressuring her to sell the family home and move into a smaller place. She agrees that the house is too big for one person, but it is full of memories and she just loves the garden that she and her husband spent years growing together.

When you try to explain hearing aid options to Mrs Smith, she seems absent minded and asks the same questions repeatedly. She says that money is no problem and that she would feel more comfortable if you just chose the best hearing aid for her."

\section{Case Three}

"Mrs Cole is a 68 year old retiree, living with her husband of 42 years. She has a moderate SNHL bilaterally and is ready to update her hearing aids, now 5 years old. She and her husband own a caravan and spend six months of the year traveling around Australia. When you express your jealousy for her travels, she responds by saying that it was fun the first year, but then the second and third trips have not been so enjoyable. She complains that she doesn't sleep well in the caravan and that her lack of sleep causes her to feel constantly 
exhausted, too tired even to eat. You notice that she looks quite thin, but then so do a lot of

49 women her age.

50

51 When you start to probe for COSI goals, she says that she used to sometimes have difficulty 52 hearing her husband when they were bushwalking, but that she doesn't go with him

53 anymore as she prefers to watch her daytime TV shows in the caravan. Her COSI goals

54 include hearing the TV at a softer volume as she doesn't want to disturb the other campers

55 in the caravan park, and hearing her husband calling out to her when he is cooking on the

56 outside $B B Q$ while she is watching her shows inside the caravan.

57

58 When you probe as to who her other communication partners might be, she says that they 59 often make friends with the other campers in the campground. She then corrects herself, by 60 saying that her husband does this, that he chats with the other couples around the camp fire 61 at night. She says that she'd like to join them, but that she's got nothing interesting to add to 62 the conversation and gets worried that they may not like her, so she stays inside.

63

64 She says that she is interested in a pair of hearing aids that will link into the TV so that her 65 husband can listen to his music, while she watches her shows."

66

67

68

69

70 
Appendix 2. Audiologists' usual response when clients present with emotional and psychological concerns and/or symptoms in the

\begin{tabular}{|c|c|c|c|c|}
\hline Theme & Sub-theme & $\begin{array}{c}\text { Condensed meaning unit } \\
\text { (number of meaning units) } \\
\text { Case One: Depression }\end{array}$ & $\begin{array}{c}\text { Condensed meaning unit } \\
\text { (number of meaning units) } \\
\text { Case Two: Grief }\end{array}$ & $\begin{array}{l}\text { Condensed meaning unit } \\
\text { (number of meaning units) } \\
\text { Case Three: Depression }\end{array}$ \\
\hline \multicolumn{5}{|c|}{ Informational counselling } \\
\hline & & Fatigue and its impact (2) & $\begin{array}{l}\text { Identify whether she is on any } \\
\text { medication (1) }\end{array}$ & Discuss stress and anxiety (1) \\
\hline & & General health (2) & & $\begin{array}{l}\text { Discuss methods for managing } \\
\text { anxiety (1) }\end{array}$ \\
\hline & & & & $\begin{array}{l}\text { Discuss sleeping difficulties and } \\
\text { recommend ways to improve sleep } \\
\text { (2) }\end{array}$ \\
\hline & \multicolumn{4}{|c|}{ Counsel regarding audiological symptoms or rehabilitative options } \\
\hline & & $\begin{array}{l}\text { Explain the psychosocial impacts of } \\
\text { hearing loss (8) }\end{array}$ & $\begin{array}{l}\text { Discuss psychosocial impacts of } \\
\text { hearing loss ( } 3 \text { ) }\end{array}$ & $\begin{array}{l}\text { Discuss psychosocial impacts of } \\
\text { hearing loss (5) }\end{array}$ \\
\hline & & Identify communication needs (9) & $\begin{array}{l}\text { Identify the client's goals for hearing } \\
\text { rehabilitation (2) }\end{array}$ & Discuss communication goals ( 7 ) \\
\hline & & $\begin{array}{l}\text { Counsel client on audiological } \\
\text { benefits of amplification (11) }\end{array}$ & $\begin{array}{l}\text { Discuss audiological benefit of } \\
\text { amplification ( } 2 \text { ) }\end{array}$ & $\begin{array}{l}\text { Discuss audiological benefits of } \\
\text { hearing aids (4) }\end{array}$ \\
\hline & & $\begin{array}{l}\text { Counsel on psychosocial benefits of } \\
\text { amplification (29) }\end{array}$ & $\begin{array}{l}\text { Discuss psychosocial benefits of } \\
\text { hearing aids (4) }\end{array}$ & $\begin{array}{l}\text { Discuss psychosocial benefits of } \\
\text { hearing aids (5) }\end{array}$ \\
\hline & & $\begin{array}{l}\text { Listen to her concerns regarding her } \\
\text { old hearing aids (1) }\end{array}$ & & \\
\hline
\end{tabular}




\section{Diagnostic testing \\ Conduct diagnostic \\ testing / screening}

Administer routine clinical surveys (1)

Perform further audiological testing

(CAPD \& hearing in noise tests) (1)
Administer routine clinical surveys (1)

Hearing assessment (1)

Administer routine clinical surveys (1)

Hearing assessment (1)

Hearing aid review (1)

Investigate health issues, e.g. has she lost weight (1)

Administer questionnaires evaluating insomnia, depression \& anxiety (1)

Interventions

Discuss, order, fit or modify hearing devices

Persuade to take action towards audiological rehabilitation (2)

Recommend new hearing aids (16)

Order new hearing aids (5)

Discuss assistive listening devices (6) Encourage use of existing hearing aids (8)

Modify hearing aid settings (3)
Explore her readiness for hearing aids

(3)

Provide information on hearing aids (8)

Fit with entry level Free-To-Client (government funded) hearing aids (3) Proceed with hearing aid fitting/tria (18)

Fit her with a loan aid (1)

Encourage her to discuss hearing aid options with her family (1)

Discuss hearing aid return options (1)
Fix / review current hearing aids (4)

Discuss/ provide information on hearing aids (24)

Discuss/ provide information on

hearing aid accessories (3)

Discuss assistive listening devices (4)

Suggest new hearing aids to encourage social reengagement (2)

Hearing aid fitting/ trial (21)

assistive listening devices fitting / trial (3)

Encourage hearing aid use (1) 
Modify home listening environment

Encourage her to try new things with the hearing aids (1)

Book home visit to modify listening

environments (1)

\section{Encourage social participation}

Recommend social engagement

activities (3)

Encourage her to re-engage socially

Establish a network of

communication partners (1)

Try to motivate the client to re-

engage (3)

Provide/offer communication training

Provide communication training (1)

Provide communication training (2)

Provide communication training (7)

Provide communication training to

husband (3)

\section{Clinical processes}

\section{Delay audiological rehabilitative care to focus on psychological/psychosocial concerns}

I would not force new hearing aids on her (1)

\section{Ensure clinician continuity}

Ensure clinician continuity (1)

Slow down

Slow down the rehabilitation

program process (2)

Slow down the appointment (1)

Provide ongoing support

Keep in touch (1)
Delay hearing aid discussion or fitting allowing time for the client to grieve

Slow down the appointment and rehabilitation program (6)

Follow up with a phone call (2) 
Ensure ongoing contact with client (1)

Prioritise client safety

If the client seems like they intend on

hurting themselves, I would not

release them until appropriate on-

going support had been arranged

through the GP (1)

\section{Design a rehabilitation plan that considers psychosocial concerns raised}

Make a plan together (1)

Shared decision making (6)

Help the client find hope (1)

Establish a daily routine for her (1)

\section{Make time for non-audiological discussion during the appointment}

Make time for non-audiological

discussion during the appointment

(5)

\section{Involve significant others}

Encourage the client to bring family

to future appointments (6)

Rebook the appointment with family present (1)

Involve significant others (9)
Provide info on hearing aids to take home and discuss with her family (5)

\section{CC family into GP report} recommending hearing aids (1)

Offer to take call from clients family to answer any questions they may have regarding the hearing aids (1) Book another appointment for significant other to attend (not specifically for hearing aid fitting) (3)
Encourage her to bring her husband to future appointments (5)

Ask her husband to attend future appointments to gain a better understanding of their communication behaviours (1)

Involve husband in the consultation (7)

Encourage husband to actively support the client regarding better hearing, e.g. wear lapel mic (2) 
Ask significant others to assist with hearing aid management (1)

Book another appointment for significant other to attend to discuss hearing aids (14)

Recommend she involve her family in the hearing aid decision process (7)

Ask/encourage the client to bring a significant other (e.g. daughter) to

future appointments (15)
Address only the audiologically relevant symptoms and disregard psychosocial or psychological symptoms raised
Ask if she would like for her husband to be involved in future appointments (2)

Treat only the audiologically relevant issues (2)

\section{Emotional support (Emotion-focussed}

counselling)

\section{Use active \\ listening and \\ encourage \\ dialogue}

Use active listening (7)

Ask questions to further explore psychosocial experiences

Ask questions to further explore

psychosocial experiences (8)

\section{Express concern for client's well-being}

\section{Use client-centred communication}

\author{
Be empathetic (2)
}

Express sympathy (1)
Use active listening (26)

Encourage dialogue (2)

Ask questions to further explore psychosocial experiences (8)

Express concerns regarding her social isolation (1)

Be empathetic (3)

Express sympathy (3)

\section{Be empathetic (3)}


Exhibit a friendly attitude (1)

Make their visits as enjoyable as

possible (1)

Care (1)

Build rapport (1)

Acknowledge and validate the clients' feelings

Acknowledge and validate the clients' feelings (6)

Validate the client's self-worth (7)

Focus on her psychosocial needs

Identify the clients support system (7)

Counsel on the impacts of social

withdrawal (1)

Counsel on the need for social

interaction (1)

Focus on her emotional needs

Address her emotional needs (3)

Introduce a positive perspective (2)

Use therapeutic counselling techniques

Use of specific counselling techniques

(e.g. CBY, NLP, Solution-based

therapy) (2)
Be present (1)

Acknowledge and validate the clients' feelings (9)

Normalise the grieving process (3)

Identify the clients support system (2)

Address her emotional needs (9)

Introduce a positive perspective (1)

Express awe at her ability to attend the audiology appointment (1)
Provide emotional reassurance (2)

Introduce a positive perspective (1)

Name the clients' feelings (6)

Normalise the clients' experiences (1)

Explore whether her social

withdrawal is due to the hearing loss or other factors (13)

Discuss psychological benefits of social connection/engagement (7)

Discuss her goals for improved emotional well-being (2)

Share positive stories of past clients and my own family that relate to her situation 
Establish whether she has support during this time

\begin{tabular}{|l} 
Impose clinician views on client \\
Counter argue clients concerns (1)
\end{tabular}

Share positive stories of past clients and my own family that relate to her situation (2)

Establish whether she has support during this time (3)

Make assumptions about her situation (1)

Lay out a course of action for her (1)

Discuss benefits of planning living arrangements before they become necessary (because of mobility issues, etc.) (1)

Disregard daughters concerns and support the clients wishes to stay in her own home (1)

\section{Involve /referral to} external help

\section{Hostel staff}

Involve hostel staff in hearing aid management (4)

Discuss her communication needs with the hostel staff (3)

Provide communication training to the Hostel staff (2)

Recommend the client discuss her feelings with her carers at the hostel (3)
Establish whether she has support during this time (1)
Offer advice (1) 
Make contact with the Hostel

regarding her psychological needs

(16)

Make contact with Hostel staff -

reason not specified (4)

Make contact with the Hostel staff to

discuss medication (1)

GP

Report to GP regarding hearing aids

Make contact with the GP regarding psychosocial symptoms (28)

Recommend the client discusses her feelings with her GP (6)

Make contact with the GP - reasons not specified (3)

Seek clients permission to contact her GP (3)

\section{Mental health practitioners}

Recommend she seek help from a

mental health practitioner (7)

\section{Family and significant others}

Enquire about whether or not she has previously discussed feelings with anyone (6)

Seek clients permission to contact family (2)
Report to GP recommending hearing aids (1)

Suggest seeking help from her GP (3)

GP letter / referral / contact - reason not specified (6)

Seek permission to contact GP (1)

Ask if she is receiving support from her GP (1)
Ask whether the client has discussed her symptoms with her GP or another professional (2)

Make contact with her GP regarding psychosocial concerns (3)

Recommend the client seek help from her GP for psychological symptoms (3)

Recommend the client discuss her medical symptoms with her GP (e.g. loss of appetite and insomnia) (6)

Involve GP - reason not specified (8)

Recommend the client seek support from a mental health practitioner (3)

Encourage husband to support her with social re-engagement (2)

Talk with the family (2)

Discuss support options with family
Ask whether the client has discussed her symptoms with her husband (4) 
Recommend she discusses her feelings with somebody/family (5)

Discuss my concerns with her family (4)

Enquire level of support from family (6)

Social workers

\section{Community}

services

Seek social work support (1)

Seek out community services to support social re-engagement for the client (1)

\section{Professional support - general}

External help - non-specific (1)
Direct her to speak with her family about her worries/grief (1)

Contact her daughter to explain the clients condition (1)

Recommend she seek pastoral

support from her church for her grief (1)

Ensure she has support at church for grieving process (1)

Ensure she has support at gardening club for grieving process (1)

Suggest support services, such as meals on wheels, home help, cheap taxi fare booklets, and silver chain nursing (1)

Recommend she seek help for grief management (7)

Ask the client whether she is receiving any support for her grief (2)
Encourage her to talk with her husband about her feelings (5)

Ask husband his thoughts on the situation (3) 


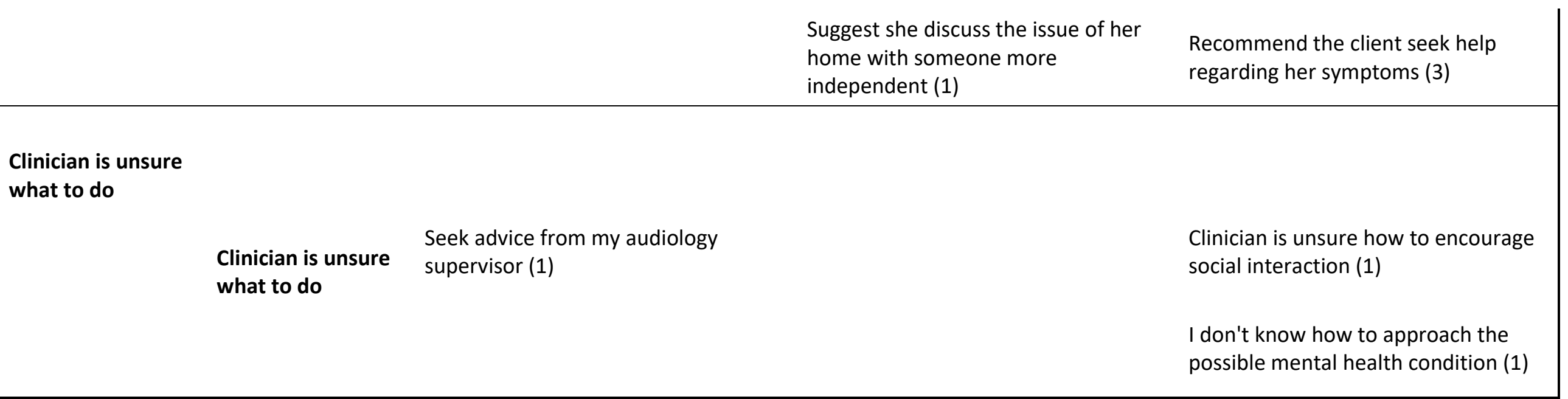

